\title{
A Picard-Mann hybrid iterative process
}

Safeer Hussain Khan ${ }^{*}$

"Correspondence:

safeerhussain5@yahoo.com;

safeer@qu.edu.qa

Department of Mathematics,

Statistics and Physics, Qatar

University, Doha, 2713, State of

Qatar

\begin{abstract}
We introduce a new iterative process which can be seen as a hybrid of Picard and Mann iterative processes. We show that the new process converges faster than all of Picard, Mann and Ishikawa iterative processes in the sense of Berinde (Iterative Approximation of Fixed Points, 2002) for contractions. We support our analytical proof by a numerical example. We prove a strong convergence theorem with the help of our process for the class of nonexpansive mappings in general Banach spaces and apply it to get a result in uniformly convex Banach spaces. Our weak convergence results are proved when the underlying space satisfies Opial's condition or has Fréchet differentiable norm or its dual satisfies the Kadec-Klee property.
\end{abstract}

MSC: $47 \mathrm{H} 10 ; 54 \mathrm{H} 25$

Keywords: contraction; nonexpansive mapping; iterative process; fixed point; rate of convergence; weak convergence; strong convergence

\section{Introduction and preliminaries}

Let $C$ be a nonempty convex subset of a normed space $E$, and let $T: C \rightarrow C$ be a mapping. Throughout this paper, $\mathbb{N}$ denotes the set of all positive integers, $I$ the identity mapping on $C$ and $F(T)$ the set of all fixed points of $T$.

The Picard or successive iterative process [2] is defined by the sequence $\left\{u_{n}\right\}$ :

$$
\left\{\begin{array}{l}
u_{1}=u \in C, \\
u_{n+1}=T u_{n}, \quad n \in \mathbb{N} .
\end{array}\right.
$$

The Mann iterative process [3] is defined by the sequence $\left\{v_{n}\right\}$ :

$$
\left\{\begin{array}{l}
v_{1}=v \in C, \\
v_{n+1}=\left(1-\alpha_{n}\right) v_{n}+\alpha_{n} T v_{n}, \quad n \in \mathbb{N},
\end{array}\right.
$$

where $\left\{\alpha_{n}\right\}$ is in $(0,1)$.

The sequence $\left\{z_{n}\right\}$ defined by

$$
\left\{\begin{array}{l}
z_{1}=z \in C, \\
z_{n+1}=\left(1-\alpha_{n}\right) z_{n}+\alpha_{n} T y_{n}, \\
y_{n}=\left(1-\beta_{n}\right) z_{n}+\beta_{n} T z_{n}, \quad n \in \mathbb{N},
\end{array}\right.
$$

where $\left\{\alpha_{n}\right\}$ and $\left\{\beta_{n}\right\}$ are in $(0,1)$, is known as the Ishikawa iterative process [4].

\section{Springer}

C 2013 Khan; licensee Springer. This is an Open Access article distributed under the terms of the Creative Commons Attribution License (http://creativecommons.org/licenses/by/2.0), which permits unrestricted use, distribution, and reproduction in any medium, provided the original work is properly cited. 
The Ishikawa process can be seen as a 'double Mann iterative process' or 'a hybrid of Mann process with itself'. In this paper, we introduce a new process which we call 'PicardMann hybrid iterative process.' Our process for one mapping case is given by the sequence $\left\{x_{n}\right\}$

$$
\left\{\begin{array}{l}
x_{1}=x \in C, \\
x_{n+1}=T y_{n}, \\
y_{n}=\left(1-\alpha_{n}\right) x_{n}+\alpha_{n} T x_{n}, \quad n \in \mathbb{N},
\end{array}\right.
$$

where $\left\{\alpha_{n}\right\}$ is in $(0,1)$. This process is independent of all Picard, Mann and Ishikawa iterative processes since $\left\{\alpha_{n}\right\}$ and $\left\{\beta_{n}\right\}$ are in $(0,1)$. Even if it is allowed to take $\alpha_{n}=1$ to make it a special case of the Ishikawa iterative process, our process is faster than Ishikawa and 'faster is better' rule should prevail.

The purpose of this paper is to prove that our process (1.4) converges faster than all of Picard, Mann and Ishikawa iterative processes for contractions in the sense of Berinde [1]. We support our analytical proof by a numerical example. We also prove a strong convergence theorem with the help of our process for the class of nonexpansive mappings in general Banach spaces and apply it to get a result in uniformly convex Banach spaces. We also prove some weak convergence results when the underlying space satisfies Opial's condition or has the Fréchet differentiable norm or its dual satisfies the Kadec-Klee property.

Let $S=\{x \in E:\|x\|=1\}$, and let $E^{*}$ be the dual of $E$. The space $E$ has (i) Gâteaux differentiable norm if

$$
\lim _{t \rightarrow 0} \frac{\|x+t y\|-\|x\|}{t}
$$

exists for each $x$ and $y$ in $S$; (ii) Fréchet differentiable norm if for each $x$ in $S$, the above limit exists and is attained uniformly for $y$ in $S$, and in this case, it is also well known that

$$
\langle h, J(x)\rangle+\frac{1}{2}\|x\|^{2} \leq \frac{1}{2}\|x+h\|^{2} \leq\langle h, J(x)\rangle+\frac{1}{2}\|x\|^{2}+b(\|h\|)
$$

for all $x, h$ in $E$, where $J$ is the Fréchet derivative of the functional $\frac{1}{2}\|\cdot\|^{2}$ at $x \in X,\langle\cdot, \cdot\rangle$ is the dual pairing between $E$ and $E^{*}$, and $b$ is an increasing function defined on $[0, \infty)$ such that $\lim _{t \downarrow 0} \frac{b(t)}{t}=0$; (iii) Opial's condition [5] if for any sequence $\left\{x_{n}\right\}$ in $E, x_{n} \rightarrow x$ implies that lim $\sup _{n \rightarrow \infty}\left\|x_{n}-x\right\|<\lim \sup _{n \rightarrow \infty}\left\|x_{n}-y\right\|$ for all $y \in E$ with $y \neq x$; and (iv) the KadecKlee property if for every sequence $\left\{x_{n}\right\}$ in $E, x_{n} \rightarrow x$ and $\left\|x_{n}\right\| \rightarrow\|x\|$ together imply $x_{n} \rightarrow$ $x$ as $n \rightarrow \infty$. Examples of Banach spaces satisfying Opial's condition are Hilbert spaces and all spaces $l^{p}(1<p<\infty)$. On the other hand, $L^{p}[0,2 \pi]$ with $1<p \neq 2$ fail to satisfy Opial's condition. Uniformly convex Banach spaces, Banach spaces of finite dimension and reflexive locally uniform convex Banach spaces are some of the examples of reflexive Banach spaces which satisfy the Kadec-Klee property.

A mapping $T: C \rightarrow E$ is demiclosed at $y \in E$ if for each sequence $\left\{x_{n}\right\}$ in $C$ and each $x \in E, x_{n} \rightarrow x$ and $T x_{n} \rightarrow y$ imply that $x \in C$ and $T x=y$.

Lemma 1 [6] Suppose that $E$ is a uniformly convex Banach space and $0<p \leq t_{n} \leq q<$ 1 for all $n \in \mathbb{N}$. Let $\left\{x_{n}\right\}$ and $\left\{y_{n}\right\}$ be two sequences of $E$ such that $\lim _{\sup _{n \rightarrow \infty}}\left\|x_{n}\right\| \leq$ 
$r$, limsup $\sup _{n \rightarrow \infty}\left\|y_{n}\right\| \leq r$ and $\lim _{n \rightarrow \infty}\left\|t_{n} x_{n}+\left(1-t_{n}\right) y_{n}\right\|=r$ hold for some $r \geq 0$. Then $\lim _{n \rightarrow \infty}\left\|x_{n}-y_{n}\right\|=0$.

Lemma 2 [7] Let $C$ be a nonempty bounded closed convex subset of a uniformly convex Banach space, and let $T: C \rightarrow C$ be a nonexpansive mapping. Then there is a strictly increasing and continuous convex function $g:[0,1) \rightarrow[0,1)$ with $g(0)=0$ such that

$$
g(\|T(t x+(1-t) y)-(t T x+(1-t) T y)\|) \leq\|x-y\|-\|T x-T y\|
$$

for all $x, y \in C$ and $t \in[0,1]$.

Lemma 3 [8] Let E be a uniformly convex Banach space satisfying Opial's condition, and let $C$ be a nonempty closed convex subset of $E$. Let $T: C \rightarrow C$ be a nonexpansive mapping. Then I-T is demiclosed with respect to zero.

Lemma 4 [9] Let E be a reflexive Banach space such that $E^{*}$ has the Kadec-Klee property. Let $\left\{x_{n}\right\}$ be a bounded sequence in $E$ and $x^{*}, y^{*} \in W=\omega_{w}\left(x_{n}\right)$ (weak limit set of $\left\{x_{n}\right\}$ ). Suppose that $\lim _{n \rightarrow \infty}\left\|t x_{n}+(1-t) x^{*}-y^{*}\right\|$ exists for all $t \in[0,1]$. Then $x^{*}=y^{*}$.

The following definitions about the rate of convergence are due to Berinde [1]. See also Sahu [10].

Definition 1 Let $\left\{a_{n}\right\}$ and $\left\{b_{n}\right\}$ be two sequences of real numbers converging to $a$ and $b$ respectively. If

$$
\lim _{n \rightarrow \infty} \frac{\left|a_{n}-a\right|}{\left|b_{n}-b\right|}=0
$$

then $\left\{a_{n}\right\}$ converges faster than $\left\{b_{n}\right\}$.

Definition 2 Suppose that for two fixed-point iterative processes $\left\{u_{n}\right\}$ and $\left\{v_{n}\right\}$, both converging to the same fixed point $p$, the error estimates

$$
\begin{array}{ll}
\left\|u_{n}-p\right\| \leq a_{n} & \text { for all } n \in \mathbb{N}, \\
\left\|v_{n}-p\right\| \leq b_{n} & \text { for all } n \in \mathbb{N},
\end{array}
$$

are available where $\left\{a_{n}\right\}$ and $\left\{b_{n}\right\}$ are two sequences of positive numbers converging to zero. If $\left\{a_{n}\right\}$ converges faster than $\left\{b_{n}\right\}$, then $\left\{u_{n}\right\}$ converges faster than $\left\{v_{n}\right\}$ to $p$.

In the sequel, whenever we talk of rate of convergence, we mean the one given by the above definitions.

\section{Rate of convergence}

We now show that (1.4) converges at a rate faster than all of Picard (1.1), Mann (1.2) and Ishikawa (1.3) iterative processes for contractions.

Proposition 1 Let $C$ be a nonempty closed convex subset of a normed space E, and let $T$ be a contraction of $C$ into itself. Suppose that each of the iterative processes (1.1), (1.2), 
(1.3) and (1.4) converges to the same fixed point $p$ of $T$ where $\left\{\alpha_{n}\right\}$ and $\left\{\beta_{n}\right\}$ are such that $0<\lambda \leq \alpha_{n}, \beta_{n}<1$ for all $n \in \mathbb{N}$ and for some $\lambda$. Then the iterative process given by (1.4) converges faster than all the other three processes.

Proof Let $p$ be a fixed point of $T$. Then for Picard iterative process (1.1), we have

$$
\begin{aligned}
\left\|u_{n+1}-p\right\| & =\left\|T u_{n}-p\right\| \\
& \leq \delta\left\|u_{n}-p\right\| \\
& \vdots \\
& \leq \delta^{n}\left\|u_{1}-p\right\| .
\end{aligned}
$$

Let

$$
a_{n}=\delta^{n}\left\|u_{1}-p\right\|
$$

Mann iterative process (1.2) gives

$$
\begin{aligned}
\left\|v_{n+1}-p\right\| & =\left\|\left(1-\alpha_{n}\right)\left(v_{n}-p\right)+\alpha_{n}\left(T v_{n}-p\right)\right\| \\
& \leq\left(1-\alpha_{n}\right)\left\|v_{n}-p\right\|+\alpha_{n} \delta\left\|v_{n}-p\right\| \\
& =\left(1-(1-\delta) \alpha_{n}\right)\left\|v_{n}-p\right\| \\
& \leq(1-(1-\delta) \lambda)\left\|v_{n}-p\right\| \\
& \vdots \\
& \leq(1-(1-\delta) \lambda)^{n}\left\|v_{1}-p\right\| .
\end{aligned}
$$

Let

$$
b_{n}=(1-(1-\delta) \lambda)^{n}\left\|v_{1}-p\right\| .
$$

Our process (1.4) gives

$$
\begin{aligned}
\left\|x_{n+1}-p\right\| & =\left\|T y_{n}-p\right\| \\
& \leq \delta\left\|y_{n}-p\right\| \\
& \leq \delta\left\|\left(1-\alpha_{n}\right)\left(x_{n}-p\right)+\alpha_{n}\left(T x_{n}-p\right)\right\| \\
& =\delta\left[\left(1-\alpha_{n}\right)\left\|x_{n}-p\right\|+\alpha_{n} \delta\left\|x_{n}-p\right\|\right] \\
& =\delta\left(1-(1-\delta) \alpha_{n}\right)\left\|x_{n}-p\right\| \\
& \leq \delta(1-(1-\delta) \lambda)\left\|x_{n}-p\right\| \\
& \vdots \\
& \leq[\delta(1-(1-\delta) \lambda)]^{n}\left\|x_{1}-p\right\| .
\end{aligned}
$$


Let

$$
c_{n}=[\delta(1-(1-\delta) \lambda)]^{n}\left\|x_{1}-p\right\| .
$$

Now $\frac{c_{n}}{a_{n}}=\frac{[\delta(1-(1-\delta) \lambda)]^{n}\left\|x_{1}-p\right\|}{\delta^{n}\left\|u_{1}-p\right\|}=[(1-(1-\delta) \lambda)]^{n} \frac{\left\|x_{1}-p\right\|}{\left\|u_{1}-p\right\|} \rightarrow 0$ as $n \rightarrow \infty$. Thus $\left\{x_{n}\right\}$ converges faster than $\left\{u_{n}\right\}$ to $p$. Similarly, $\frac{c_{n}}{b_{n}}=\frac{[\delta(1-(1-\delta) \lambda)]^{n}\left\|x_{1}-p\right\|}{(1-(1-\delta) \lambda)^{n}\left\|\nu_{1}-p\right\|}=\delta^{n} \frac{\left\|x_{1}-p\right\|}{\left\|v_{1}-p\right\|} \rightarrow 0$ as $n \rightarrow \infty$. It is not difficult to prove that for the Ishikawa iterative process, we have $\left\|z_{n+1}-p\right\| \leq(1-(1-\delta) \lambda-$ $\left.(1-\delta) \lambda^{2} \delta\right)^{n}\left\|z_{1}-p\right\| \leq(1-(1-\delta) \lambda)^{n}\left\|z_{1}-p\right\|$, and hence $\left\{x_{n}\right\}$ converges faster than $\left\{z_{n}\right\}$ to $p$.

Summing up, we conclude that our process (1.4) converges faster than all of Picard (1.1), Mann (1.2) and Ishikawa (1.3) iterative processes.

We support our above analytical proof by a numerical example.

Example 1 Let $E=\mathbb{R}$ and $C=[1, \infty)$. Let $T: C \rightarrow C$ be an operator defined by $T(x)=$ $\sqrt{x^{2}-8 x+40}$ for all $x \in C$. It is not difficult to show that $T$ is a contraction. Choose $\alpha_{n}=\frac{3}{4}$, $\beta_{n}=\frac{3}{4}$ for all $n$ with initial value $x_{1}=20$. In order to compare our iterative process (1.4) with those of Picard, Mann and Ishikawa, first ten iterations for all these have been given in Table 1. All the processes converge to the same fixed point $p=5$. It is clear from Table 1 that our process converges faster than all above mentioned processes up to an accuracy of seven decimal places.

Remark The above calculations have been repeated by taking different values of parameters $\alpha_{n}$ and $\beta_{n}$. It has been verified every time that our iterative process (1.4) converges faster than all Picard, Mann and Ishikawa iterative processes. Moreover, it has been observed that as the values of $\alpha_{n}$ and $\beta_{n}$ go far below 0.5 and near 0 (above 0.5 and near 1), the convergence gets slower (faster), and it happens with every scheme except Picard as it has nothing to do with these parameters. For example, when $\alpha_{n}=\frac{1}{4}, \beta_{n}=\frac{1}{4}$ for all $n$, the values for the above four processes at the tenth iteration become 5.0000582, 5.0011640, $12.3847322,10.88505847$, respectively. The accuracy of seven decimal places is obtained by our process at the 14th iteration. The values at this iteration for the above processes are 5.0000000, 5.0000018, 9.8671409, 8.2715668. By the way, for $\alpha_{n}=\frac{1}{2}, \beta_{n}=\frac{1}{2}$ for all $n$, at the 12th iteration, we get $5.0000000,5.0000465,5.8689348$ and 5.1255429 , respectively.

Table 1 A comparison of our process with other processes

\begin{tabular}{lllll}
\hline Iteration \# & Our process & Picard & Mann & Ishikawa \\
\hline 0 & 20.0000000 & 20.0000000 & 20.0000000 & 20.0000000 \\
1 & 14.4083240 & 16.7332005 & 17.5499004 & 15.80624301 \\
2 & 9.5775523 & 13.6431080 & 15.1937181 & 11.99368021 \\
3 & 6.3006224 & 10.8161699 & 12.9625372 & 8.825342023 \\
4 & 5.1644139 & 8.3940558 & 10.9011812 & 6.663235026 \\
5 & 5.0139785 & 6.5808606 & 9.0727196 & 5.592734334 \\
6 & 5.0011241 & 5.5372233 & 7.5572746 & 5.192320075 \\
7 & 5.0000900 & 5.1344966 & 6.4300222 & 5.060469879 \\
8 & 5.0000072 & 5.0286263 & 5.7089159 & 5.018828059 \\
9 & 5.0000006 & 5.0058038 & 5.3185940 & 5.005844634 \\
10 & 5.0000000 & 5.0011640 & 5.1346469 & 5.0018126 \\
\hline
\end{tabular}




\section{Convergence results in uniformly convex Banach spaces}

In this section, we use the iterative process (1.4) for nonexpansive mappings to prove some convergence theorems.

Lemma 5 Let $C$ be a nonempty closed convex subset of a uniformly convex Banach space E. Let $T$ be a nonexpansive mapping of C. Let $\left\{\alpha_{n}\right\}$ be such that $0<a \leq \alpha_{n} \leq b<1$ for all $n \in \mathbb{N}$ and for some $a, b$. Let $\left\{x_{n}\right\}$ be defined by the iterative process (1.4). Then

(i) $\lim _{n \rightarrow \infty}\left\|x_{n}-q\right\|$ exists for all $q \in F(T)$.

(ii) $\lim _{n \rightarrow \infty}\left\|x_{n}-T x_{n}\right\|=0$.

Proof Let $q \in F(T)$. Then

$$
\begin{aligned}
\left\|y_{n}-q\right\| & =\left\|\left(1-\alpha_{n}\right) x_{n}+\alpha_{n} T x_{n}-q\right\| \\
& \leq\left(1-\alpha_{n}\right)\left\|x_{n}-q\right\|+\alpha_{n}\left\|T x_{n}-q\right\| \\
& \leq\left\|x_{n}-q\right\|,
\end{aligned}
$$

and so

$$
\begin{aligned}
\left\|x_{n+1}-q\right\| & =\left\|T y_{n}-q\right\| \\
& \leq\left\|y_{n}-q\right\| \\
& \leq\left\|x_{n}-q\right\| .
\end{aligned}
$$

This shows that $\left\{\left\|x_{n}-q\right\|\right\}$ is decreasing, and this proves part (i). Let

$$
\lim _{n \rightarrow \infty}\left\|x_{n}-q\right\|=c
$$

To prove part (ii), we first prove that $\lim _{n \rightarrow \infty}\left\|y_{n}-q\right\|=c$.

Since $\left\|x_{n+1}-q\right\| \leq\left\|y_{n}-q\right\|$, therefore

$$
\liminf _{n \rightarrow \infty}\left\|x_{n+1}-q\right\| \leq \liminf _{n \rightarrow \infty}\left\|y_{n}-q\right\|,
$$

and so

$$
c \leq \liminf _{n \rightarrow \infty}\left\|y_{n}-q\right\|
$$

On the other hand, (3.1) implies that

$$
\limsup _{n \rightarrow \infty}\left\|y_{n}-q\right\| \leq c .
$$

Reading it together with (3.3), we get

$$
\lim _{n \rightarrow \infty}\left\|y_{n}-q\right\|=c
$$

Next, $\left\|T x_{n}-q\right\| \leq\left\|x_{n}-q\right\|$ implies that

$$
\limsup _{n \rightarrow \infty}\left\|T x_{n}-q\right\| \leq c
$$


Using (3.2), (3.4), (3.5) and Lemma 1, we obtain

$$
\lim _{n \rightarrow \infty}\left\|x_{n}-T x_{n}\right\|=0 .
$$

Lemma 6 For any $p_{1}, p_{2} \in F(T), \lim _{n \rightarrow \infty}\left\|t x_{n}+(1-t) p_{1}-p_{2}\right\|$ exists for all $t \in[0,1]$ under the conditions of Lemma 5.

Proof By Lemma $5, \lim _{n \rightarrow \infty}\left\|x_{n}-p\right\|$ exists for all $p \in F(T)$, and therefore $\left\{x_{n}\right\}$ is bounded. Thus there exists a real number $r>0$ such that $\left\{x_{n}\right\} \subseteq D \equiv \overline{B_{r}(0)} \cap C$, so that $D$ is a closed convex nonempty subset of $C$. Put

$$
f_{n}(t)=\left\|t x_{n}+(1-t) p_{1}-p_{2}\right\|
$$

for all $t \in[0,1]$. Then $\lim _{n \rightarrow \infty} f_{n}(0)=\left\|p_{1}-p_{2}\right\|$ and $\lim _{n \rightarrow \infty} f_{n}(1)=\lim _{n \rightarrow \infty}\left\|x_{n}-p_{2}\right\|$ exist. Let $t \in(0,1)$.

Define $B_{n}: D \rightarrow D$ by

$$
\begin{aligned}
& B_{n} x=T A_{n} x, \\
& A_{n} x=\left(1-\alpha_{n}\right) x+\alpha_{n} T x .
\end{aligned}
$$

Then $B_{n} x_{n}=x_{n+1}, B_{n} p=p$ for all $p \in F(T)$. It is not hard to show that

$$
\left\|A_{n} x-A_{n} y\right\| \leq\|x-y\|
$$

and

$$
\left\|B_{n} x-B_{n} y\right\| \leq\|x-y\| .
$$

Set

$$
R_{n, m}=B_{n+m-1} B_{n+m-2} \cdots B_{n}, \quad m \geq 1
$$

and

$$
v_{n, m}=\left\|R_{n, m}\left(t x_{n}+(1-t) p_{1}\right)-\left(t R_{n, m} x_{n}+(1-t) p_{1}\right)\right\| .
$$

Now

$$
\begin{aligned}
\left\|R_{n, m} x-R_{n, m} y\right\| & \leq\left\|B_{n+m-1} B_{n+m-2} \cdots B_{n} x-B_{n+m-1} B_{n+m-2} \cdots B_{n} y\right\| \\
& \leq\left\|B_{n+m-2} \cdots B_{n} x-B_{n+m-2} \cdots B_{n} y\right\| \\
& \leq\left\|B_{n+m-3} \cdots B_{n} x-B_{n+m-3} \cdots B_{n} y\right\| \\
& \vdots \\
& \leq\|x-y\| .
\end{aligned}
$$


Moreover, $R_{n, m} x_{n}=x_{n+m}$ and $R_{n, m} p=p$ for all $p \in F(T)$. By Lemma 2, there exists a strictly increasing continuous function $g:[0,1) \rightarrow[0,1)$ with $g(0)=0$ such that

$$
\begin{aligned}
g\left(v_{n, m}\right) & =\left\|x_{n}-p_{1}\right\|-\left\|R_{n, m} x_{n}-R_{n, m} p_{1}\right\| \\
& =\left\|x_{n}-p_{1}\right\|-\left\|x_{n+m}-p_{1}\right\| .
\end{aligned}
$$

Since $\lim _{n \rightarrow \infty}\left\|x_{n}-p\right\|$ exists for all $p \in F(T), g\left(v_{n, m}\right) \rightarrow 0$ as $n \rightarrow \infty$. Hence $v_{n, m} \rightarrow 0$ as $n \rightarrow \infty$.

Finally, from the inequality

$$
\begin{aligned}
f_{n+m}(t) & =\left\|t x_{n+m}+(1-t) p_{1}-p_{2}\right\| \\
& \leq v_{n, m}+\left\|R_{n, m}\left(t x_{n}+(1-t) p_{1}\right)-p_{2}\right\| \\
& \leq v_{n, m}+\left\|t x_{n}+(1-t) p_{1}-p_{2}\right\| \\
& =v_{n, m}+f_{n}(t),
\end{aligned}
$$

we have $\lim \sup _{m \rightarrow \infty} f_{n+m}(t) \leq \lim \sup _{m \rightarrow \infty} v_{n, m}+f_{n}(t)$.

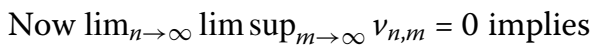

$$
\limsup _{n \rightarrow \infty} f_{n}(t) \leq \liminf _{n \rightarrow \infty} f_{n}(t)
$$

so that $\lim _{n \rightarrow \infty}\left\|t x_{n}+(1-t) p_{1}-p_{2}\right\|$ exists for all $t \in[0,1]$.

Lemma 7 Assume that all the conditions of Lemma 5 are satisfied. Then, for any $p_{1}, p_{2} \in$ $F(T), \lim _{n \rightarrow \infty}\left\langle x_{n}, J\left(p_{1}-p_{2}\right)\right\rangle$ exists; in particular, $\left\langle p-q, J\left(p_{1}-p_{2}\right)\right\rangle=0$ for all $p, q \in \omega_{w}\left(x_{n}\right)$, the set of all weak limits of $\left\{x_{n}\right\}$.

Proof The proof is the same as that of Lemma 2.3 of [11] and is therefore omitted here.

We now give our weak convergence theorem.

Theorem 1 Let E be a uniformly convex Banach space, and let $C, T$ and $\left\{x_{n}\right\}$ be taken as in Lemma 5. Assume that (a) E satisfies Opial's condition or (b) $E$ has a Fréchet differentiable norm, or (c) the dual $E^{*}$ of $E$ satisfies the Kadec-Klee property. If $F(T) \neq \phi$, then $\left\{x_{n}\right\}$ converges weakly to a point of $F(T)$.

Proof Let $p \in F(T)$. Then $\lim _{n \rightarrow \infty}\left\|x_{n}-p\right\|$ exists as proved in Lemma 5. By the boundedness of $\left\{x_{n}\right\}$ and reflexivity of $E$, we have a subsequence $\left\{x_{n_{i}}\right\}$ of $\left\{x_{n}\right\}$ that converges weakly in $C$. We prove that $\left\{x_{n}\right\}$ has a unique weak subsequential limit in $F(T)$. For this, let $u$ and $v$ be weak limits of the subsequences $\left\{x_{n_{i}}\right\}$ and $\left\{x_{n_{j}}\right\}$ of $\left\{x_{n}\right\}$, respectively. By Lemma 5 , $\lim _{n \rightarrow \infty}\left\|x_{n}-T x_{n}\right\|=0$ and $I-T$ is demiclosed with respect to zero by Lemma 3; therefore, we obtain $T u=u$. Again, in the same fashion, we can prove that $v \in F(T)$. Next, we prove the uniqueness. To this end, first assume (a) is true. If $u$ and $v$ are distinct, then by Opial's 
condition,

$$
\begin{aligned}
\lim _{n \rightarrow \infty}\left\|x_{n}-u\right\| & =\lim _{n_{i} \rightarrow \infty}\left\|x_{n_{i}}-u\right\| \\
& <\lim _{n_{i} \rightarrow \infty}\left\|x_{n_{i}}-v\right\| \\
& =\lim _{n \rightarrow \infty}\left\|x_{n}-v\right\| \\
& =\lim _{n_{j} \rightarrow \infty}\left\|x_{n_{j}}-v\right\| \\
& <\lim _{n_{j} \rightarrow \infty}\left\|x_{n_{j}}-u\right\| \\
& =\lim _{n \rightarrow \infty}\left\|x_{n}-u\right\| .
\end{aligned}
$$

This is a contradiction, so $u=v$. Next assume (b). By Lemma 7, $\left\langle p-q, J\left(p_{1}-p_{2}\right)\right\rangle=0$ for all $p, q \in \omega_{w}\left(x_{n}\right)$. Therefore $\|u-v\|^{2}=\langle u-v, J(u-v)\rangle=0$ implies $u=v$. Finally, say (c) is true. Since $\lim _{n \rightarrow \infty}\left\|t x_{n}+(1-t) u-v\right\|$ exists for all $t \in[0,1]$ by Lemma 6 , therefore $u=v$ by Lemma 4 . Consequently, $\left\{x_{n}\right\}$ converges weakly to a point of $F$ and this completes the proof.

A mapping $T: C \rightarrow C$, where $C$ is a subset of a normed space $E$, is said to satisfy Condition (I) [12] if there exists a nondecreasing function $f:[0, \infty) \rightarrow[0, \infty)$ with $f(0)=0$, $f(r)>0$ for all $r \in(0, \infty)$ such that $\|x-T x\| \geq f(d(x, F(T)))$ for all $x \in C$, where $d(x, F(T))=$ $\inf \{\|x-p\|: p \in F(T)\}$.

Theorem 2 Let $E$ be a real Banach space, and let $C, T,\left\{x_{n}\right\}$ be taken as in Lemma 5. Then $\left\{x_{n}\right\}$ converges to a point of $F(T)$ if and only if $\liminf _{n \rightarrow \infty} d\left(x_{n}, F(T)\right)=0$, where $d(x, F(T))=$ $\inf \{\|x-p\|: p \in F(T)\}$.

Proof Necessity is obvious. Suppose that $\liminf _{n \rightarrow \infty} d\left(x_{n}, F(T)\right)=0$. As proved in Lemma 5, $\lim _{n \rightarrow \infty}\left\|x_{n}-w\right\|$ exists for all $w \in F(T)$; therefore, $\lim _{n \rightarrow \infty} d\left(x_{n}, F(T)\right)$ exists. But by the hypothesis, $\liminf _{n \rightarrow \infty} d\left(x_{n}, F(T)\right)=0$, we have $\lim _{n \rightarrow \infty} d\left(x_{n}, F(T)\right)=0$. On lines similar to [13], $\left\{x_{n}\right\}$ is a Cauchy sequence in a closed subset $C$ of a Banach space $E$; therefore, it must converge to a point in $C$. Let $\lim _{n \rightarrow \infty} x_{n}=q$. Now $\lim _{n \rightarrow \infty} d\left(x_{n}, F(T)\right)=0$ gives that $d(q, F(T))=0$. Thus $q \in F(T)$.

Note that this condition is weaker than the requirement that $T$ is demicompact or $C$ is compact, see [12]. Applying Theorem 2, we obtain a strong convergence of the process (1.4) under Condition (I) as follows.

Theorem 3 Let E be a real uniformly convex Banach space, and let $C, T,\left\{x_{n}\right\}$ be taken as in Lemma 5. Let $T$ satisfy Condition (I), then $\left\{x_{n}\right\}$ converges strongly to a fixed point of $T$.

Proof We proved in Lemma 5 that

$$
\lim _{n \rightarrow \infty}\left\|x_{n}-T x_{n}\right\|=0
$$

From Condition (I) and (3.6), we get

$$
\lim _{n \rightarrow \infty} f\left(d\left(x_{n}, F(T)\right)\right) \leq \lim _{n \rightarrow \infty}\left\|x_{n}-T x_{n}\right\|=0
$$


That is,

$$
\lim _{n \rightarrow \infty} f\left(d\left(x_{n}, F(T)\right)\right)=0
$$

Since $f:[0, \infty) \rightarrow[0, \infty)$ is a nondecreasing function satisfying $f(0)=0, f(r)>0$ for all $r \in(0, \infty)$, therefore we have

$$
\lim _{n \rightarrow \infty} d\left(x_{n}, F(T)\right)=0
$$

Now all the conditions of Theorem 2 are satisfied; therefore, by its conclusion, $\left\{x_{n}\right\}$ converges strongly to a point of $F(T)$.

\section{Competing interests}

The author declares that he has no competing interests.

\section{Received: 24 May 2012 Accepted: 4 March 2013 Published: 25 March 2013}

\section{References}

1. Berinde, V: Iterative Approximation of Fixed Points. Efemeride, Baia Mare (2002)

2. Picard, E: Memoire sur la theorie des equations aux derivees partielles et la methode des approximations successives. J. Math. Pures Appl. 6, 145-210 (1890)

3. Mann, WR: Mean value methods in iterations. Proc. Am. Math. Soc. 4, 506-510 (1953)

4. Ishikawa, S: Fixed points by a new iteration method. Proc. Am. Math. Soc. 44, 147-150 (1974)

5. Opial, Z: Weak convergence of the sequence of successive approximations for nonexpansive mappings. Bull. Am. Math. Soc. 73, 591-597 (1967)

6. Schu, J: Weak and strong convergence to fixed points of asymptotically nonexpansive mappings. Bull. Aust. Math. Soc. 43, 153-159 (1991)

7. Bruck, RE: A simple proof of the mean ergodic theorem for nonlinear contractions in Banach spaces. Isr. J. Math. 32 , 107-116 (1997)

8. Browder, FE: Nonlinear Operators and Nonlinear Equations of Evolution in Banach Spaces. Proc. Symp. Pure Math., vol. 18. Proc. Amer. Math. Soc., Providence, RI (1976)

9. Kaczor, W: Weak convergence of almost orbits of asymptotically nonexpansive semigroups. J. Math. Anal. Appl. 272, 565-574 (2002)

10. Sahu, DR: Applications of the S-iteration process to constrained minimization problems and split feasibility problems. Fixed Point Theory 12(1), 187-204 (2011)

11. Khan, SH, Kim, JK: Common fixed points of two nonexpansive mappings by a modified faster iteration scheme. Bull. Korean Math. Soc. 47(5), 973-985 (2010). doi:10.4134/BKMS.2010.47.5.973

12. Senter, HF, Dotson, WG: Approximating fixed points of nonexpansive mappings. Proc. Am. Math. Soc. 44(2), 375-380 (1974)

13. Tan, KK, Xu, HK: Approximating fixed points of nonexpansive mappings by the Ishikawa iteration process. J. Math. Anal. Appl. 178, 301-308 (1993)

\section{Submit your manuscript to a SpringerOpen ${ }^{\circ}$ journal and benefit from:}

- Convenient online submission

- Rigorous peer review

- Immediate publication on acceptance

- Open access: articles freely available online

- High visibility within the field

- Retaining the copyright to your article 